\title{
Hygienic practices during menstruation among adolescent school girls
}

\author{
F Salim ${ }^{1}$, N Begum ${ }^{2}$
}

\begin{abstract}
Objective : To assess the hygienic practices during menstruation among adolescent school girls in selected secondary rural schools.

Methods : This descriptive, cross-sectional study was conducted from November to December, 2015. Study area was selected on choice were four upazilas of Kishoreganj, Lakshmipur, Barguna and Sirajganj District. From the study area 15 schools were selected on the basis of convenience and accessibility. Data were collected from 438 purposively selected adolescent unmarried school girls aged $15-18$ years and studying in class IX and $X$, through face to face interview by pretested questionnaire. Data were analyzed by using software SPSS version 20.

Results : The result of the study revealed that majority (52\%) participants were using cloths and $48.4 \%$ were using sanitary napkin for menstrual hygiene management. About half of the participants got the information about menstrual and reproductive health from family members. Thirty five percent (35\%) girls do not attend school during first two days of menstruation. Majority (69\%) of the girls never change pad and 45\% complained about unavailability of water at school. However, knowledge of reproductive health issues like minimum age at marriage (18yrs, 85.8\%), minimum age of child birth (20yrs, 89\%) and need for extra nutrition during pregnancy $(99.0 \%)$ was quite satisfactory. The level of maternal education and economic condition were significantly associated with sanitary napkin use.

Conclusion : The study revealed that higher percentage of participants was not using sanitary napkins, although their knowledge regarding menstrual and reproductive health issues is satisfactory. Implementation of school health programs for adolescents should emphasis on menstrual hygiene management.
\end{abstract}

Keywords : Adolescent girls, Menstruation, Menstrual hygiene management (MHM)

Northern International Medical College Journal Vol. 7 No. 02 January 2016, Page 139-142

\section{${ }^{1}$ Dr. Farhana Salim Assistant Professor Dept. of Community Medicine Shahid Monsur Ali Medical College, Dhaka}

\section{${ }^{2}$ Dr. Nasreen Begum Assistant professor Community Medicine Northern International Medical College, Dhaka}

\author{
Correspondence \\ Dr. Farhana Salim \\ Assistant Professor \\ Dept. of Community Medicine \\ Shahid Monsur Ali Medical \\ College, Dhaka \\ Email : farhanasalim@yahoo.com
}

Introduction: World Health Organization defines adolescents as people between 10 and 19 years old ${ }^{1}$. It is a unique period of age characterized by significant physical, cognitive, emotional and social changes ${ }^{2}$. It is a time when development sets the course for either a healthy or unhealthy adulthood ${ }^{3}$. Adolescence is marked in girls with the onset of menstruation. Adolescent school girls who are experiencing menstruation for the first time, menstrual hygiene management (MHM) is constrained by environmental, social, economic and cultural factors such as expense of commercial sanitary napkins, lack of water and latrine facilities, lack of private rooms for changing sanitary pads, limited education about the facts of menstrual hygiene and an estimated 1.3 million adolescents died in 2012, mostly from preventable or treatable causes ${ }^{6,4}$.

Many girls are not even aware of menstruation before their menarche. The lack of access to reliable sources of information on reproductive health means that girls and even adult women may hold misconceptions about the physiology of menstruation and its management. Due to unavailability of sanitary products, large number of female population in Bangladesh has to rely mostly on old cloths to manage their menstrual bleeding ${ }^{7}$. Poor menstrual management is a major cause of absenteeism from school. When a school girl misses significant days of academic lessons, it affects her performances which in turn may cause her to drop out from school.

As a taboo topic in many cultures, the process and management of menstruation is often shrouded in mystery. Cultural restriction and discriminatory gender roles exacerbate women's difficulties during 
menstruation. ${ }^{6,4}$ In schools, there is usually a lack of education regarding menstrual and reproductive health. Menstrual hygiene management directly contributes to improving maternal health. Due to its indirect effect on school absenteeism and gender discrepancy, poor menstrual hygiene and management may seriously hamper the achievement of SDG-4 on quality education and SDG-5 on gender equality. MHM is an issue that is inadequately addressed in Bangladesh.

Misconceptions, lack of information and adverse attitudes towards menstruation may lead to a negative self-image among girls who are experiencing menstruation for the first time and the culture of silence around menstrual hygiene further increases the perception of menstruation as shameful event that needs to be hidden. ${ }^{3}$ Thus, to break the silence of taboo and successfully manage menstrual hygiene, adolescents need to understand the biologic change they are experiencing and be equipped with the skills to cope with it.

However studies addressing awareness of hygienic practices during menstruation is limited in Bangladesh. Thus the objective of this study is to assess the awareness and knowledge related to menstrual hygiene management among adolescence school girls at rural setting.

\section{Materials and methods}

This descriptive cross-sectional study was conducted from November to December, 2015. From fifteen rural girl's schools four on choice selected upazilas of Kishoreganj, Lakshmipur, Barguna and Sirajganj District (Kuliarchar, Ramgoti, Barguna Sadar and Sirajganj Sadar upazilas respectively). The schools were selected based on convenience and accessibility by the study team members. Prior informed consent was taken from the schools Headmaster or Mistress and the participating girls. Data were collected from 438 adolescent unmarried school girls aged $15-18$ years and studying in class IX and X selected purposively. A pretested questionnaire was administered for obtaining information related to menstrual hygiene management practices and knowledge and treatment seeking behavior about menstrual and reproductive health problems.

\section{Data processing and analysis}

The data were analyzed by preparing master sheet. Tables of descriptive statistics were prepared to present and analyze the major findings as per the study objectives by using soft ware SPSS version 20.

\section{Results}

\section{Socio-demographic characteristics of participants}

Four hundred thirty eight female students participated in the study. The mean age of the study participants was 15.74 (SD \pm
0.858). Among the participants, $45.4 \%$ were $14-15$ years of age and $54.6 \%$ were from class $X$. The mean age of menarche of the participants was $12.02(S D \pm 3.215)$ years. Majority of the participants $85.8 \%$ reported of having regular cycle. The fathers of majority students $33.8 \%$ were businessmen and mothers $89.7 \%$ were housewives. Majority of mother's education was primary level $47 \%$. (Table-I)

\section{Table-I: Distribution of socio-demographic characteristics; $\mathrm{N}=438$}

\begin{tabular}{|c|c|c|}
\hline Age group & No of respondents & Percent \\
\hline $14-15$ years & 199 & 45.4 \\
\hline $16-17$ years & 221 & 50.4 \\
\hline 18 years and more & 18 & 4.1 \\
\hline \multicolumn{3}{|c|}{ Mean $=15.74 ;(S D \pm 0.858)$} \\
\hline \multicolumn{3}{|c|}{ Attending Classes } \\
\hline Class IX & 199 & 45.4 \\
\hline Class X & 239 & 54.6 \\
\hline \multicolumn{3}{|l|}{ Age at menarche } \\
\hline$<10$ years & 14 & 3.2 \\
\hline $10-11$ years & 171 & 39.0 \\
\hline $12-13$ years & 230 & 52.5 \\
\hline \multicolumn{3}{|c|}{ Mean $=12.02 ;(S D= \pm 3.215)$} \\
\hline \multicolumn{3}{|c|}{ Menstrual cycle } \\
\hline Regular & 376 & 85.8 \\
\hline Irregular & 62 & 14.2 \\
\hline \multicolumn{3}{|c|}{ Mother's education } \\
\hline Illiterate & 68 & 15.5 \\
\hline Primary level & 206 & 47.0 \\
\hline Secondary level & 121 & 27.6 \\
\hline Higher secondary & 40 & 9.1 \\
\hline Degree and above & 3 & 0.7 \\
\hline \multicolumn{3}{|c|}{ Father's occupation } \\
\hline Agriculture worker & 90 & 20.5 \\
\hline Day labourer & 78 & 17.8 \\
\hline Service holder & 91 & 20.8 \\
\hline Business & 148 & 33.8 \\
\hline Others & 31 & 7.1 \\
\hline \multicolumn{3}{|c|}{ Mother's occupation } \\
\hline House wife & 393 & 89.7 \\
\hline Agriculture worker & 10 & 2.3 \\
\hline Day labourer & 11 & 2.5 \\
\hline Service holder & 16 & 3.7 \\
\hline Others & 8 & 1.8 \\
\hline \multicolumn{3}{|c|}{ Monthly family income } \\
\hline 4000 & 96 & 21.9 \\
\hline 5000 & 4 & 9 \\
\hline 7000 & 5 & 1.1 \\
\hline 8000 & 164 & 37.4 \\
\hline 9000 & 12 & 2.7 \\
\hline 10000 & 157 & 35.8 \\
\hline
\end{tabular}


Majority of the students informed that they got advice on menstrual hygiene management (MHM) from family members (mother, sister) $48.4 \%$, whereas $14.4 \%$ from school teachers. About $18 \%$ told they do not consult anyone.

\section{Table-II : Source of information about MHM}

\section{Source of information regarding menstrual hygiene}

Family members (Mother, sister) 212

School teachers

48.4

Friends

63

14.4

Relatives

Do not consult any one

About $51.6 \%$ respondents informed about using cloths during menstruation, whereas $48.4 \%$ were using sanitary napkins. When asked about the reason for not using sanitary napkins $42.5 \%$ told they were suggested by family members; $36.7 \%$ said sanitary napkins are costly. Other reasons were ignorance $11.9 \%$ and unavailability $8.8 \%$. Most of the respondents $76.5 \%$ dry washed sanitary cloths in room and shaded places. Majority of the students $68.9 \%$ never change sanitary napkin/cloths during school time. About $60.3 \%$ respondents clean themselves with plain water during sanitary napkin changing and 45\% complained about unavailability of water in school. Regarding disposal used materials during menses $50.7 \%$ dispose to a specific site, whereas $5.7 \%$ throw anywhere. (Table-III)

Table-III: Information regarding menstrual hygiene management

$\begin{array}{lcc}\text { Materials used during menstruation } & \text { No of respondents } & \text { Percent } \\ \text { Sanitary napkin } & 212 & 48.4 \\ \text { Cloths/rag } & 226 & 51.6 \\ \text { Reasons for not using sanitary napkins } & & \\ \text { Ignorant } & 27 & 11.9 \\ \text { Costly } & 83 & 36.7 \\ \text { Not available } & 20 & 8.8 \\ \text { Suggested by family members to use cloth } & 96 & 42.5 \\ \text { Habit of drying washed sanitary clothes } & & \\ \text { Open place } & 53 & 23.5 \\ \text { Shaded place/ in the room } & 173 & 76.5 \\ \text { Frequency of changing napkins at school } & & \\ \text { Once } & 115 & 26.3 \\ \text { Twice/Thrice } & 21 & 4.8 \\ \text { None } & 302 & 68.9 \\ \text { Habit of cleaning during sanitary napkin changing } & \\ \text { Plain water } & 264 & 60.3 \\ \text { Warm water } & 110 & 25.1 \\ \text { Warm water with salt } & 6 & 1.4 \\ \text { Water mixed with savlon /dettol } & 58 & 13.2 \\ \text { Disposal of used sanitary napkin/cloth } & & \\ \text { Throw anywhere } & 25 & 5.7 \\ \text { Dispose to a specific dumping site } & 222 & 50.7 \\ \text { Wash clothes and reuse it } & 191 & 43.6\end{array}$

Majority of the respondents told about unusual feeling like unclean sensation, irritability during menstruation $78.3 \%$ and

$35.2 \%$ do not attend school during the first 2 days of menstruation. Regarding menstrual problems $65.5 \%$ respondents complained about dysmenorrhoea. When asked about other reproductive health problems majority $47.0 \%$ complained about lower abdominal pain. (Table-IV)

\section{Table-IV: Information regarding menstrual and reproductive} health problems

Menstrual and reproductive health problemsNo of respondentsPercent

Feeling during menstruation

Feel irritable/ unclean $\quad 343 \quad 78.3$

$\begin{array}{lll}\text { Feel as usual } & 95 & 21.7\end{array}$

School attendance during menses

Don't attend school during 1st 2 days of menses 154

Attend school during 1st 2 days of menses $284 \quad 64.8$

Suffering from any of the menstrual disorders

$\begin{array}{lll}\text { Amenorrhea } & 15 & 3.4\end{array}$

$\begin{array}{lll}\text { Menorrhagia } & 65 & 14.8\end{array}$

Dysmenorrhea $\quad 287 \quad 65.5$

2-3 times bleeding in one month $\quad 6 \quad 1.4$

Having no problem $\quad 36 \quad 8.2$

Suffering from other reproductive health problems

$\begin{array}{lll}\text { Excessive vaginal discharge } & 116 & 26.4\end{array}$

Itching of the genitalia $\quad 26 \quad 5.9$

$\begin{array}{lll}\text { Ulceration of genitalia } & 8 & 1.8\end{array}$

Lower abdominal pain $\quad 206 \quad 47.0$

$\begin{array}{lll}\text { Have no problem } & 82 & 18.7\end{array}$

Majority of the respondents $40 \%$ receive treatment from health workers, whereas $37 \%$ from village doctors. Only $9.8 \%$ receive treatment from M.B.B.S doctors. (Table: $\mathrm{V}$ )

\section{Table V : Treatment seeking pattern for menstrual or other} reproductive health problems

$\begin{array}{lcc}\text { Homeopathic Doctor } & 26 & 5.9 \\ \text { Kabiraj } & 5 & 1.1 \\ \text { Health workers } & 177 & 40.4 \\ \text { Upazila Health Complex } & 20 & 4.6 \\ \text { MBBS doctor } & 43 & 9.8 \\ \text { Village doctor } & 162 & 37.0\end{array}$

Mothers education and family income were found to have highly significant association $(p<0.0001)$ with sanitary napkin use. (Table-VI)

Table-VI : Association of maternal and sanitary napkin use Sanitary napkin Sanitary napkin Total $\mathrm{N}=438$ Significance user; $\mathrm{N}=212(\%)$ non-user; $\mathrm{N}=226(\%) \quad$ test

Maternal education

\begin{tabular}{lrcrl} 
Illiterate & $100(36.5)$ & $174(63.5)$ & $274(62.6 \%)$ & $\mathrm{p}<0.0001$ \\
Literate & $112(68.3)$ & $52(31.7)$ & $164(37.4 \%)$ & \\
\multicolumn{2}{l}{ Monthly family income (Tk) } & & & \\
Taka 8000 & $32(30.5 \%)$ & $73(69.5 \%)$ & $105(24 \%)$ & $\mathrm{p}<0.0001$ \\
Taka $>8000$ & $180(54.1)$ & $153(45.9)$ & $333(76 \%)$ &
\end{tabular}


Discussion : This school based cross-sectional study tried to assess hygienic practices during menstruation and menstrual hygiene management. The present study revealed that the mean age of menarche was $12.02 \pm 3$. It was lower than the findings among school girls of Amhara Province, Ethiopia and rural girls in Nagpur, India where it was 14.7 and 13.5 respectively. 8 , This difference could be attributed to the influence of both heredity and socio-economic conditions, mainly nutrition. Above $50 \%$ of the respondents received the information about menstrual and reproductive health from mothers and close family members, whereas around $14 \%$ from school teachers; only $5 \%$ get the informations from media like radio and television According to Bangladesh National Hygiene Baseline Survey, 2014; over $90 \%$ of women and girls surveyed across households get these informations from female relatives, which indicate there was lack of formal information and mass media was playing a limited role regarding these issues. ${ }^{7}$

The study revealed that $52 \%$ of the participants were using cloths and $48 \%$ were using sanitary napkins for menstrual hygiene management; whereas in the National Baseline survey, using of cloths during menstruation was as high as $80 \% .^{7}$ The present study finding has similar finding as that among high school girls of Ethiopia which may be due to education, accessibility and ability to utilize the reproductive health information. ${ }^{8}$ Majority of the participants were suggested by family members for using cloths for MHM. Forty seven percent girls using cloths used today in hiding and shaded places, which almost corresponds with the result of Bangladesh National Hygiene Baseline Survey, 2014. ${ }^{7}$ Majority of the students never change pads during school time due to lack of privacy and proper sanitary facilities, and $45 \%$ complained about unavailability of water.

Majority dispose of used sanitary materials to a particular place and According to National Hygiene Baseline Survey, 2014; only $11 \%$ of school had separate toilet for girls with water facilities and $3 \%$ had facility to dispose of sanitary products. Our study finding showed that, majority of participants felt unclean and irritable during their menses, which corroborate with findings of study done on adolescent school girls in India ${ }^{10}$. About 35\% of the girls did not attend school during first two days of menstruation, which almost substantiate with the findings of National Hygiene Baseline Survey, where the percentage was 40. The absenteeism due to menstruation interferes with the school performances. Instead of menstruation being a monthly event to be managed easily and comfortably, it was a source of difficulty and discomfort for a large number of students, with possible long term impact on learning. In the present study, large number of girls complained about dysmenorrhoea (about 65\%) as a menstrual problem and lower abdominal pain (47\%) as reproductive health problem. Less complained problems was menorrhagia, unusual vaginal discharge etc. The findings were more or less similar to study done on adolescent school girls in India. ${ }^{10}$

Regarding treatment seeking pattern for menstrual or other reproductive health problems, it was found that majority (40\%) of the girls seek advice from health workers (e.g. FWA or HA); $37 \%$ go to the village doctors. Very few (only 9.8\%) consult M.B.B.S doctors. In a study done by Kabir et al among unmarried female adolescents, $40 \%$ female adolescents sought treatment from qualified physicians ${ }^{11}$. The treatment seeking behaviors by adolescents for menstrual problem was explained by individual levels of comfort and familiarity of the providers as well as with accessibility of services. The current study showed strong association of maternal education and use of sanitary napkins by the respondents, which means proper menstrual hygiene management. Students whose mother had attended elementary school or higher education showed good knowledge about menstrual hygiene management as compared to students whose mothers had never attended formal education. Similarly higher economic condition showed positive association with sanitary napkin use and better menstrual hygiene management. These findings are comparable with findings from Ethiopia, Mumbai and Nigeria. $8,12,13$.

Conclusion : Based on the findings of the present study, it can be concluded that use of sanitary products for MHM is related to maternal education and economic conditions. A large scale study including all the variables related to hygienic practices during menstruation is required to obtain further information to find out the real situation.

\section{References}

1. World Health Organization (2015) Global Standards for quality health care-services for adolescents. Available: http://apps.who.int/iris/bitstream/10665/183935/1/ 9789241549332_vol1_eng.pdf?ua=1

2. National adolescent health information centre, University of California (2004) Improving the health of adolescents and young adults. Available: http://nahic.ucsf.edu/wpcontent/uploads/2011/11/Complete2010Guide.pdf

3. UNESCO (2014) Puberty education and menstrual hygiene management. Available: http://unesdoc.unesco.org/images/0022/002267/226792e.pdf

4. Loughborough University (2012). Menstruation hygiene management for school girls in low income countries. Available: http://wedc.lboro.ac.uk/resources/factsheets/ FS007_MHM_A4_Pages.pdf

5. World Health Organization. Adolescents: health risks and solution. Available: http://www.who.int/mediacentre/factsheets/fs345/en/

6. Bangladesh Demographic and Health Survey 2011, NIPORT, January 2013; 71

7. Bangladesh National Hygiene Baseline Survey, Preliminary Report, June 2014; MOLGRD, ICDDRB, Water Aid Bangladesh.

8. Teklemariam G, Desta H and Yinager W (2014) Age of Menarche and Knowledge about Menstrual Hygiene Management among Adolescent School Girls in Amhara Province, Ethiopia: Implication to Health Care Workers \& School Teachers .[PMC free article] [PubMed]

9. Durge PM, Warapande U. Impact of assess of health education in adolescent girls. J Obst Gyn 1995;41:46-50

10. Singh M M, Devi R, Gupta SS. Awareness and health seeking behaviour of rural adolescent school girls on menstrual and reproductive health problems. Indian Journal of Medical Sciences 1999; 10:439-443.

11. Kabir H, Saha NC, Wirtz AL, Gazi R. Treatment-seeking for selected reproductive health problems: behaviours of unmarried female adolescents in two low-performing areas of Bangladesh. BioMed Central; Kabir et al. Reproductive Health 2014, 11:54. Available: http://www.reproductive-health-journal.com/content/11/1/54

12. Prateek B, Saurabh S (2011) A cross sectional study of knowledge and practices about reproductive health among female adolescents in An Urban Slum of Mumbai.Journal of Family and Reproductive Health 5(4): 117-124.

13. Abioye EA (200) Menstrual knowledge and practices amongst secondary school girls in llelfe, Nigeria. The journal of royal society for the promotion of health 120(1): 23-26[PubMed] 